\title{
ESPOLIAÇÃO E EXCEÇÃO NAS METRÓPOLES BRASILEIRAS: O CASO DO PAC NA REGIẪO METROPOLITANA DO RIO DE JANEIRO
}

\author{
T.O.L.Matiolli ${ }^{1}$; A.C.Christovão ${ }^{2}$
}

1 Universidade de São Paulo, 05508-900, Butantã, São Paulo, Brasil

2 Universidade Federal do Rio de Janeiro, 21941-914, Rio de Janeiro-RJ, Brasil

*thiagoolmatiolli@gmail.com

\section{RESUMO}

O presente trabalho traz uma reflexão que é fruto de uma pesquisa que visou fazer o monitoramento das obras do Programa de Aceleração do Crescimento (PAC) na Região Metropolitana do Rio Janeiro (RMRJ). Após dois anos de pesquisa e a partir deste objeto empírico, pretende-se pensar a gestão das cidades brasileiras na última década, no contexto do governo Lula, em particular, cuja atuação é pensada em um debate sobre a possibilidade de um Novo-Desenvolvimentismo, uma vez que esse governo é marcado por uma presença mais forte do Estado na construção de infraestrutura econômica e em esforços no combate às desigualdades sociais.

PALAVRAS-CHAVE: PAC, gestão urbana, Novo-Desenvolvimentismo, exceção, acumulação por despossessão.

\section{SPOLIATION AND EXCEPTION IN BRAZILIAN METROPOLISES: THE PAC CASE IN THE METROPOLITAN REGION OF RIO DE JANEIRO}

\begin{abstract}
This paper presents a reflection that is the result of a survey which intended to monitor the works of the Growth Acceleration Program (PAC) in the Metropolitan Region of Rio de Janeiro (RMRJ). After two years of research and from this empirical object, we intend to think the management of Brazilian cities over the past decade in the context of the Lula Government, in
\end{abstract}

particular, whose performance is considered in a discussion about the possibility of a NewDevelopmentalism, since this government is marked by a strong presence of the state in the construction of economic infrastructure and efforts to combat social inequalities.

KEYWORDS: PAC, urban management, New-Developmentalism, exception, accumulation by dispossession. 


\section{INTRODUÇÃO}

O presente trabalho traz uma reflexão que é fruto de uma pesquisa que visou fazer o monitoramento das obras do Programa de Aceleração do Crescimento (PAC) na Região Metropolitana do Rio Janeiro. Após dois anos de pesquisa e a partir deste objeto empírico, pretende-se pensar a gestão das cidades brasileiras na última década, no contexto do governo Lula, em particular, cuja atuação é pensada em um debate sobre a possibilidade de um NovoDesenvolvimentismo, uma vez que esse governo é marcado por uma presença mais forte do Estado na construção de infraestrutura econômica e em esforços no combate às desigualdades sociais.

Sem querer esgotar o tema e apenas buscando contribuir para reflexão sobre a cidade e sua produção em formas contemporâneas, a partir dos elementos acima citados, o texto traz os resultados de uma extensa pesquisa sobre algumas intervenções do PAC na Região Metropolitana do Rio de Janeiro e algumas questões de fundo (ou hipóteses de trabalho) que o orientam, quais sejam (questões essas que serão retomadas ao fim do artigo): sem querer definir o governo lula como desenvolvimentista ou não, mas buscando os efeitos de poder desse debate (dessa racionalidade de Estado, de governo) sobre a vida cotidiana das cidades, no nosso caso, nas grandes intervenções federais em habitação e saneamento, busca-se compreender as ações estatais no território, reconhecendo as diversas alianças e lutas de classe que são estabelecidas (Harvey, 2007), configurando coerências estruturadas (ibid, 2006) em mais um momento da acumulação por despossessão ou espoliação (ibid, 2003; 2007) distintas nesses territórios, o que pode ser possível de enxergar através da análise do PAC na Região Metropolitana do Rio de Janeiro.

Dentro deste contexto capitalista, mas reconhecendo a peculiaridade brasileira, busca-se entender o PAC nos termos das gramáticas políticas sugeridas por Edson Nunes (Nunes, 1994; Cardoso e Júnior, 2003), em uma relação de continuidade com os modelos de desenvolvimento e racionalidades que lhe foram pretéritas, criando uma conformação contemporânea que reproduz um Estado de exceção (Oliveira, 2003), uma vez que toma o mercado como soberano e segue uma lógica de urgências, que se manifesta em uma cidadania escassa (1994).

Por fim, nessa configuração de dada aliança de classe, de uma coerência estrutura situada, dos termos de um insulamento burocrático, da lógica de um Estado de exceção (que desemboca numa cidadania escassa), a participação popular é bloqueada, seja na construção de um projeto na lógica da gestão democrática da cidade, seja na difusão de informações necessárias para um controle social das ações do Estado, ou ainda por retirar o direito à cidade do horizonte da intervenção estatal.

Para trabalhar as questões/hipóteses supracitadas, o artigo segue a seguinte estrutura: primeiro, uma apresentação do que é o PAC; seguido pela exposição do escopo da pesquisa; num terceiro momento, pelos resultados obtidos por ela; e, por fim, uma análise em que tais questões são analisadas a luz dos dados ora apresentados.

\section{REVISÂO BIBLIOGRÁFICA}

Lançado em 2007 o Programa de Aceleração do Crescimento (PAC) é apresentado como objeto de um novo modelo de desenvolvimento e padrão de crescimento econômico, ao mesmo tempo em que é uma iniciativa tomada também para combater os efeitos econômicos e sociais negativos da crise financeira internacional. Esse discurso de novidade na forma de ação estatal e realização de políticas públicas, está inserido também em um debate que se realiza no seio do governo Lula, entre uma ação política mais ou menos desenvolvimentista. 
A análise das respostas do governo brasileiro para a crise de 2008, que não se reduzem ao PAC, deve se iniciar um pouco antes, com a eleição de Luiz Inácio Lula da Silva para a presidência da república. Nos seus dois mandatos, inicia-se uma discussão sobre o caráter e o papel do Estado brasileiro, debate que é mantido no governo de sua sucessora, Dilma Rousseff. A questão é se, nas formas de atuação estatal, estaríamos de frente a um Novo Desenvolvimentismo, que seria uma modalidade do que se chama de Capitalismo de Estado, de forte inspiração keynesiana (Pinho, 2011).

O adjetivo "novo" se explica, pois durante grande parte do século XX, basicamente de 1930 a 1980, pensadores (Economistas, cientistas sociais, historiadores...) na tentativa de explicar a dinâmica econômica e política do país, e atores políticos e parlamentares, caracterizaram a forma de ação do governo como nacional-desenvolvimentismo.

O que caracteriza o nacional-desenvolvimentismo, basicamente é: a presença de um Estado forte e intervencionista, com vistas a regular a economia e promover o crescimento econômico, dentro de um projeto nacional de desenvolvimento montado sobre um "tripé" que articula o Estado, empresas privadas nacionais e internacionais, voltado para o fortalecimento do mercado interno e utilizando sua política externa também para este fim. Segundo Pinho (2011), esse modelo relega a questão social para segundo plano, uma vez que seu desenvolvimento gerou maior concentração de renda e aumento das desigualdades sociais.

Isto posto, o Novo-Desenvolvimentismo, a tomar forma como governo Lula traz as mesmas características: a ideia de que a formação de um mercado forte, requer uma Estado forte; só um Estado e mercado fortes podem garantir taxas elevadas de crescimento; mas isso só se torna possível dentro de um projeto nacional; e a ideia de que só é possível superar desigualdades, com taxas de crescimento elevadas (Pinho 2011).

O Novo-Desenvolvimentismo estaria em continuidade com o Desenvolvimentismo do século XX, mas com foco também na distribuição da renda, na redução das desigualdades sociais, no estabelecimento de novas relaçõess entre Estado e sociedade, com ênfase na participação social e abertura democrática do governo; mas, por outro lado, também afinado com resquícios da agenda neoliberal que marcou a década de 90, principalmente a ênfase na estabilidade econômica (Pinho, 2012). Nos posicionaremos com relação a este debate na última seção deste atigo.

Inserido neste contexto, o PAC é lançado e se traduz num conjunto de medidas econômicas somadas a expressivos investimentos em infraestrutura (divididas em três eixos: energética, logística e social e urbana - vale esclarecer que nossa pesquisa concentra-se neste último eixo), fomentados pelo governo federal. Visa-se, assim criar condições macro setoriais para contribuir no crescimento do país, englobando um conjunto de políticas públicas a serem aplicadas na totalidade do território brasileiro, no período de 2007 a 2010, com o objetivo de promover a aceleração do crescimento econômico, o aumento do emprego e a melhoria das condições de vida da população (Araújo, 2012).

Segundo declaração do ministro Guido Mantega (Apud, Araújo, 2012), o PAC se compõe de cinco blocos. O principal bloco engloba as medidas de infraestrutura, incluindo a infraestrutura social, como habitação, saneamento e transportes de massa. Os demais blocos incluem: medidas para estimular crédito e financiamento, melhoria do marco regulatório na área ambiental, desoneração tributária e medidas fiscais de longo prazo. Essas ações deveriam ser implementadas na primeira fase do PAC, gradativamente, ao longo do quadriênio 2007 - 2010. A meta era obter um crescimento do PIB de 5\% ao ano. Isso deveria ser alcançado contornando-se os entraves para o desenvolvimento e com o resultado do papel "indutor" do setor público, já que segundo o ministro, cada $\mathrm{R} \$ 1,00$ investido pelo setor público poderia gerar $\mathrm{R} \$ 1,50 \mathrm{em}$ investimentos privados. Os 
investimentos de $\mathrm{R} \$ 503,9$ bilhões, até 2010, se constituiriam na espinha dorsal do Programa de Aceleração do Crescimento econômico para o país. Esse conjunto de projetos de infraestrutura pública deveria ajudar a acelerar os investimentos privados $(I d, 2012)$.

Com o PAC, políticas que estavam em desenvolvimento no âmbito do Ministério das Cidades - entre outras, através de Secretarias Nacionais como de Habitação e Saneamento, acabaram sendo atropeladas pela nova lógica de financiamento imposta. Por exemplo, a Política Nacional de Habitação e seu Plano Nacional, que já estava praticamente finalizado, acabaram sendo emperradas pela supremacia do Programa Minha Casa, Minha Vida (também associado ao PAC), assim como aconteceu aos recursos vinculados ao FNHIS. Na área de saneamento, impactos semelhantes também puderem ser notados. Se antes, avançávamos no sentido de uma democrática construção de políticas e planos de ações relacionados às áreas de maior interesse à população em geral, com o PAC vimos a questão do financiamento se sobrepor.

No âmbito do novo programa, o governo federal, através da Caixa Econômica, seleciona projetos que são enviados pelos governos municipais, estaduais ou mesmo outras instituições como, por exemplo, empresas, ONGs ou Organizações Populares, de todo o Brasil. Para a aprovação destes, fora previamente definido um conjunto de diretrizes (específicas para cada tipo de intervenção) que teria como fim orientar a seleção das propostas enviadas. Várias são as etapas até que se alcance a execução, de fato, das intervenções (por exemplo, licitação, contratação); assim como vários são os requisitos para que a CAIXA aprove cada uma das etapas pré-estabelecidas. Para além de possíveis lobbies, da forma como se propõe o PAC, torna-se decisiva a capacidade burocrática que os proponentes dispõem na elaboração dos projetos e na adequação destes às extensas exigências. Burocracia que, como veremos mais à frente, se torna um ator muito importante na formatação, execução e delineamento dos resultados das intervenções, ao ganhar certa autonomia e ser um pólo centralizador do poder na gestão do Programa.

Por ora, antes de continuar na análise do PAC e de suas intervenções na Região Metropolitana do Rio de Janeiro, é preciso apresentar a pesquisa, tal como foi realizada, para que fique claro o caminho percorrido até a reflexão que se tornou possível neste artigo.

\section{MATERIAIS E MÉTODOS}

Como escopo metodológico para a pesquisa, parte-se de uma literatura acerca de 'Avaliação de Políticas', que toma como princípio a ser observado a ausência de neutralidade deste processo (FIGUEIREDO e FIGUEIREDO, 1986; CARDOSO e SANTOS JUNIOR, 2003). Isto porque o estabelecimento de critérios para a atribuição de valor às ações que se pretende avaliar, ou seja, a 'avaliação política' aparece como uma etapa anterior e fundamental à avaliação de determinada política. A explicitação do modelo normativo que orienta tal avaliação, deste modo, faz-se imprescindível. Em segundo lugar, também merece destaque o fato de que não seria exaustivo avaliar somente os resultados ou a eficácia de determinada política, mas sim, partir dos objetivos explícitos a que ela se propõe, percorrendo noções como eficiência e efetividade. Deste modo, FIGUEIREDO e FIGUEIREDO (1986) esclarece que "as políticas públicas têm geralmente dois aspectos: gerar um produto físico, tangível, mensurável; ou gerar um impacto... alterando atitudes, comportamentos e/ ou opiniões".

Partindo de tais considerações, cabe esclarecer que o monitoramento do Programa de Aceleração do Crescimento aqui desenvolvido encontra-se referido normativamente às concepções de democracia e justiça social, assim como definidas por Cardoso e Santos Junior (2003). Quanto ao caráter das ações a serem avaliadas, segundo o site do governo federal brasileiro, o PAC seria um "novo conceito" em investimento de infraestrutura. O principal objetivo do PAC, e do Governo 
Federal, seria estabelecer um novo modelo de desenvolvimento econômico que combine crescimento econômico e distribuição de renda. Estar-se-ia, então, diante de uma 'ação de impacto', e sua avaliação será, portanto, referida a esta ideia, tendo como "objetivo essencial de análise as mudanças pretendidas nas condições sociais" (FIGUEIREDO e FIGUEIREDO, 1986). Seriam as ações relativas a este programa, portanto, as mais adequadas para aquilo que se pretende? Vale lembrar que, como políticas desta natureza acabam por traduzir-se em ações experimentais, a metodologia empregada em sua avaliação adquire também este caráter.

Ao final do ano de 2009, quando se inicia a formação de um grupo de pesquisa voltado para o monitoramento do Programa de Aceleração do Crescimento na Região Metropolitana do Rio de Janeiro, foi definido que este teria como principais objetivos a elaboração de uma metodologia capaz de monitorar as intervenções relacionadas a tal Programa e a disseminação desta no sentido de instrumentalizar os movimentos sociais em torno do exercício do controle social, como lhe é de direito e como cabe em um modelo referido pela democracia e justiça social.

Deste modo, tratou-se de definir as possíveis variáveis que deveriam ser mensuradas em tal processo. Foi, então, que se deparou com um primeiro - grande -obstáculo ao monitoramento do PAC, que se perpetuou ao longo de toda pesquisa: a escassez de informações qualificadas sobre as intervenções financiadas com recursos do PAC, que fossem de livre acesso à população em geral. (Diz-se 'informações qualificadas', pois propaganda massiva em torno do programa não faltou em momento algum). Figueiredo e Figueiredo (1986) já chamavam atenção para o alto grau de restrições às fontes e à precariedade de informações disponíveis, comum às pesquisas de avaliação brasileiras, que acabam trazendo empecilhos para a sua realização. Logo, com o PAC não foi diferente.

Diante de tantos empecilhos, para um monitoramento eficiente, o grupo optou pela seleção das intervenções caracterizadas pelo volume dos recursos empenhados, no contexto da RMRJ, para um olhar mais aproximado. E assim, foram selecionadas as 22 maiores obras em termos de valores e recursos a serem realizadas na RMRJ, que se realizaram em 15 territórios diferentes.

Para o monitoramento dessas intervenções, foram realizados: o acompanhamento dos relatórios, "balanços", com algum detalhamento das obras, lançados periodicamente pelo governo federal; visitas a campo, nas intervenções selecionadas, para acompanhar o andamento das obras, a percepção da obra pelos moradores, os atores (entes públicos, ong's e empreiteiras) envolvidos na obra e outras informações pertinentes; e dois estudos de caso mais aprofundados, realizados nas intervenções em Manguinhos e no Projeto Iguaçu, que contaram também com entrevistas com agentes governamentais responsáveis pelas obras.

\section{RESULTADOS E DISCUSSÃO}

\subsection{Coisas que não deram certo no PAC}

De modo geral e apresentado de forma bem sistemática, eis os resultados que foram alcançados:

1. Com relação a articulação regional - governo federal, estados e municípios, cada um dentro de seu campo de responsabilidades, devem desenvolver ações conjuntas que venham a garantir medidas como o abastecimento de água, desassoreamento regular dos rios, coleta e tratamento de esgoto, lixo e moradia digna. A ausência de planejamento articulado por parte de tais entes acaba tendo como resultado a estagnação das ações pontuais. Por exemplo, o conjunto de intervenções nos Complexos de favela do Alemão e de Manguinhos, na cidade do Rio de Janeiro se dividiram em obras realizadas pelo município e pelo estado, o que a primeira vista pode ser tomado 
como um processo de interlocução e diálogo entre distintas esferas de governo, se mostra, num olhar mais detido, numa desarticulação, uma vez que, quando da seleção de obras do PAC, a prefeitura do Rio era comandada por César Maia (DEM) enquanto o governo do estado o era por Sérgio Cabral Filho (PMDB) (o que indica a interferência da variável político-partidária na realização concreta do PAC, em que pese o processo racional e impessoal de seleção dos projetos via edital).

2. Desigualdades de investimentos entre os municípios - nota-se que existem mais investimentos relativos ao PAC propostos para determinados municípios do que para outros, por exemplo, a cidade do Rio de Janeiro, capital do estado, deverá receber cerca de um bilhão a mais em recursos para habitação e saneamento do que os oito municípios componentes da Baixada junto. Se por um lado, reconhece-se a enorme expressão populacional que representa a capital, por outro se constata que os recursos dirigidos à Baixada estão aquém das necessidades históricas da região. $\mathrm{O}$ caso ora em tela expõe a necessidade de se qualificar os territórios selecionados, reconhecer sua inserção no processo mais amplo de gestão urbana e metropolitana e, ainda, o processo histórico de hierarquização das regiões no espaço metropolitano, o que pode ser exemplificado, pelo grande aporte de recursos, novamente, nos Complexos de Manguinhos e Alemão, áreas localizadas no entorno das principais entradas da cidade e no trajeto para a Barra da Tijuca e Recreio, áreas-chave de investimento para os megaeventos que ocorrem e estão por ocorrer na capital fluminense.

3. Estímulo à competição entre os entes federativos - o PAC é uma junção entre novos projetos, projetos já em andamento ou que estavam à espera de financiamento para serem executados. Ele depende de estados e municípios apresentem suas propostas e que estas estejam de acordo com as diretrizes definidas pelo Governo Federal. Tal estratégia pode acabar por estimular disputas entre os municípios, que apresentam estruturas e capacidades desiguais de formulação de projetos e privilegiar aqueles entes que têm uma estrutura burocrático-técnica mais desenvolvida para a realização de projetos; o que se torna mais evidente frente ao curto prazo para elaboração e apresentação dos projetos ao governo federal, o qual gera o risco da falta de projetos, por municípios pouco aparelhados tecnicamente, ou mesmo a pressa para formulação dos mesmos, o que pode ser um recurso para eliminar a participação popular na elaboração dos projetos ou ainda gerar propostas com falhas que vão aparecer somente lá na execução da obra.

4. Sistema de gestão e monitoramento do PAC ineficientes- além do Comitê Gestor do PAC (compostos pelos ministros da Casa Civil, da Fazenda e do Planejamento), foi constituído o Grupo Executivo do PAC, responsável em "estabelecer metas e acompanhar a implementação do PAC". Com o objetivo de "prestar contas do PAC para a sociedade", são realizados balanços quadrimestrais que se ocupam da avaliação do andamento do Programa, assim como do acompanhamento da execução das obras monitoradas nos municípios. Além deste, o governo divulga relatórios estaduais. A análise de tais balanços, no entanto, revela a escassez de informações mais detalhadas, quando não incorretas, que podem estar relacionadas à falta de acompanhamento in loco das intervenções e centralização deste processo, tornando a pesquisa e o próprio monitoramento distantes da realidade das intervenções.

5. Ausência de detalhamento da natureza das intervenções - através dos balanços, observase que as denominações atribuídas às intervenções (por exemplo: urbanização; melhorias no sistema de abastecimento de água; ou ainda saneamento e urbanização integrado) pouco ou nada esclarecem sobre as mesmas. Não é possível, através do "balanço do PAC" conhecer que tipo de ações, de fato, inclui cada intervenção, tão pouco, estados e municípios divulgam relatórios periódicos sobre as obras as quais estão responsáveis. Deste modo, são dificultadas as ações de monitoramento das intervenções pela população local; 
6. Ausência de transparência em relação aos cronogramas das intervenções e recursos envolvidos - de mesmo modo, informações como cronograma de obras ou orçamento, especificando os valores das contrapartidas dos estados e municípios junto a cada intervenção não estão acessíveis. Sem elas torna-se impossível o trabalho de controle social, através da atuação da sociedade civil. A busca por informações através dos órgãos públicos responsáveis pelas intervenções mostrou-se demasiadamente complexa. As secretarias envolvidas fossem vinculadas ao governo do estado, ao município do Rio de Janeiro ou aos demais municípios da RMRJ, não demonstravam estarem preparadas para o repasse de informações, fosse para um órgão de pesquisa ligada à universidade, fosse a um cidadão comum interessado em obter informações sobre aquilo que se desenvolvia ao lado de sua (quando não na própria) residência. Quanto às empresas responsáveis pelo trabalho técnico social das intervenções, em geral, não estavam disponíveis telefones ou sites que pudessem esclarecer sua procedência e atuação. Havia apenas, em geral, anúncios de cursos com foco em geração de renda ou na questão do meio ambiente que em nada esclareciam a questão das obras.

Se por um lado, a presença da equipe de monitoramento nos locais das obras gerava um enorme mal estar para os funcionários, que demonstravam enorme insegurança quanto a permissão ou não de repassar as informações requeridas; por outro, os moradores demonstravam grande expectativa de que, finalmente, alguém pudesse dar a eles algum esclarecimento sobre aquilo que estava se passando em seu "quintal" - o que, de fato, não se faria possível.

7. Desarticulação com as políticas nacionais de participação - o sistema de monitoramento e gestão do PAC também não previu formas de se garantir o envolvimento dos atores e dos espaços de participação já instituídos pela política nacional de desenvolvimento urbano que vem sendo desenvolvida desde o início do governo Lula, a exemplo dos Conselhos Setoriais existentes em todo o país, seja em âmbito nacional, estaduais ou municipais.

8. Ausência de participação e controle social efetivo da população - não foram criados, pelo governo federal, mecanismos que garantissem ou, ao menos, previssem uma consulta prévia, nos estados e municípios formuladores de projetos, que envolvesse a sociedade civil para a elaboração ou aprovação daqueles a serem acolhidos pelos recursos do PAC.

9. Processos de reassentamento controversos - Em geral, em todas as intervenções de urbanização de favelas, mas também em algumas intervenções de drenagem, há numerosos casos que indicam a necessidade de remoção, seja por se tratarem de áreas de risco, como encostas de morros ou beiras de rios, seja por motivos como a aberturas de ruas, de redes de saneamento ou mesmo a instalação de novos equipamentos públicos em locais antes ocupados por famílias. Voltando aos objetivos do PAC, de início foram divulgadas, pelo governo federal, algumas diretrizes que deveriam orientar os processos de reassentamentos, voltadas para o atendimento do direito à cidade, o respeito ao direito à moradia digna e, por fim, à construção de espaços ambientalmente sustentáveis. Tais princípios deveriam nortear todas as intervenções, independente do município ou estado onde estas se davam. Para o caso da RMRJ, pôde-se perceber algumas (ir)regularidades na forma como se desenrolaram as intervenções do PAC por todos os municípios visitados.

A começar pelo direito à participação, também com relação às remoções, durante todo processo, independente do local, faltou transparência, inclusive, para os moradores sujeitos a tal ação. Não havia informações precisas sobre quem, de fato, seria realocado para uma das novas unidades habitacionais construídas pelo PAC - já que não havia unidades suficientes para todos os que deveriam sair - ou, por vezes, não havia informação alguma; muitas vezes eles nem mesmo sabiam a quem se dirigir em busca de tais informações, já que havia um enorme jogo de empurra 
entre os agentes do governo e os funcionários das empresas contratadas para o desenvolvimento do trabalho técnico social.

Ainda quanto à escolha das famílias a serem reassentadas, muitas vezes, o que foi noticiado por diversos veículos da imprensa local, foram casos onde traficantes locais obtiveram tal poder, tendo a possibilidade de beneficiar seus parentes ou aliados, em detrimento de outras famílias, de fato, necessitadas. A qualidade dos novos apartamentos, também, muitas vezes, em pouquíssimo tempo, foi posta à prova. Casos de rachaduras, infiltrações ou mesmo alagamentos foram denunciados por moradores de Manguinhos, Alemão e Rocinha, e também expostos em jornais de grande circulação. Especificamente para o caso do Projeto Iguaçu, na Baixada Fluminense, dos cinco conjuntos habitacionais prometidos, apenas um (de poucas unidades, localizado no município de Mesquita) foi entregue. Em princípio, tais conjuntos seriam construídos pela Companhia Estadual de Habitação do Estado do Rio de Janeiro (CEHAB), órgão de habitação vinculado ao governo do estado; após mais de um ano de promessas, tal acordo foi desfeito, levando o Instituto Estadual do Ambiente (INEA), também integrante do governo estadual, responsável pelas obras de drenagem, que antes necessitavam da remoção de residência da beira dos rios, a buscar novas soluções, trazendo mais atrasos às obras. Apesar de todo este impasse, enormes quantias de recursos já haviam sido empenhadas no tratamento dos terrenos a serem construídos os conjuntos, como no caso daquele que seria localizada no município de São João de Meriti - terreno que antes se traduzia num lixão, portanto um enorme procedimento de tratamento do solo se fazia necessário ou de outro, localizado no município de Nova Iguaçu - que hoje, já está descartado.

Com relação às indenizações oferecidas para que os moradores deixassem suas residências baseadas em decretos assinados em função das ações do PAC - não consideravam o valor dos terrenos, apenas das benfeitorias, desconsiderando o direito à usucapião; com isto eles não alcançavam cifras que permitissem a aquisição de um novo imóvel em condições adequadas para a moradia, muitas vezes levando novamente à ocupação irregular de áreas próximas ou afastadas. Outra modalidade para o reassentamento, o aluguel social, também apresentou, de modo recorrente, problemas: além do baixo valor, em inúmeros casos aconteceu de famílias deixarem de receber o aluguel social acertado com o governo criando o risco do despejo. Acontecimentos como os descritos acima foram observados tanto em ações do governo do estado, quanto das prefeituras; em locais como Manguinhos, Alemão, Baixada, etc.

No dia a dia de quem vivenciava a angústia de ver sua residência ser destruída, inúmeras outras formas de desrespeito foram citadas pelos moradores. A pressa e a pressão por removê-los, por exemplo, contrastava com o fato de que após sua saída os escombros de suas casas ficavam meses abandonados, sem que nenhuma ação de fato se desenrolasse no local. Para os moradores que buscavam resistir, estes tinham de conviver com tais escombros que acarretavam o surgimento de animais como ratos e as possíveis doenças causadas por eles. O não reconhecimento do valor de suas casas, conquistadas com tamanho esforço era mais uma fonte de sofrimento para estes moradores.

10. Não conclusão das obras - Finalmente, há de se destacar o fato de que não foi possível verificar in loco nenhuma das intervenções selecionadas concluídas. Apesar de, oficialmente, o PAC deveria ter sido finalizado no ano de 2010. Tal acontecimento acabava dando aos moradores a impressão de que, na verdade, o PAC representava mais do mesmo. Afinal, os tradicionais moradores destas áreas econômica e socialmente desfavorecidas por inúmeras vezes já haviam vivenciado situações semelhantes, onde um enorme volume de recursos é anunciado, porém onde as obras nunca são concluídas, ou seja, nunca servem de fato para alterar aquela dinâmica de enorme carência para quem vive no local. Produção habitacional e redes de saneamento são justamente o que precisam os moradores das favelas ou da periferia metropolitana. Porém o desperdício de 
recursos em equipamentos enormes que só servem para dar destaque a alguma atuação política (como o teleférico do Alemão; a elevação da via férrea em Manguinhos ou a passarela da Rocinha), muitas vezes, imperou junto às intervenções visitadas. Segundo os moradores, também falta qualidade: pequenas manilhas que não dão conta do escoamento do esgoto ou desassoreamentos superficiais nos rios altamente poluídos não irão resolver, realmente, os problemas locais.

\subsection{Desenvolvimento, Espoliação e Exceção}

Levando em consideração os limites de um artigo para dar conta da complexidade do que aqui está sendo abordado, e uma vez iluminados pelos dados frutos da pesquisa, apresentados acima, podemos, agora, buscar compreendê-los a partir da grade explicativa proposta para esse trabalho, apresentando também mais um ou outro caso pontual que ajude a ilustrar a reflexão.

Antes de mais nada, vamos retornar ao tema do novo-desenvolvimentismo, que orientaria as ações do governo Lula, colocando-o a partir da ótica sugerida por Michel Foucault (2008) da arte de governar, e tomando-o como uma racionalidade estatal que orienta essas ações levadas a cabo, no nosso caso pelo Estado brasileiro. Ainda que não haja espaço para uma discussão dessas no limite deste artigo, sobre a reflexão dentro do próprio governo Lula sobre a melhor forma de governar, podemos, ao menos, sugerir, a partir da grade de inteligibilidade sugerida por este autor que o novodesenvolvimentismo pode se apresentar apenas como mais uma modalidade de governo neoliberal, no qual a intervenção estatal se torna, ao contrário do que possa parecer, mais intensa, ao invés de mais rarefeita. Esse excesso de intervenção estatal é necessário para a construção de um quadro político-institucional que permite a reprodução do capitalismo e a atenção dos interesses do mercado. Pois é nesse sentido que, em sua análise Foucault descreve a construção do neoliberalismo como doutrina político-econômica, como aquela em que se define o papel do Estado como avalista de um quadro político-institucional que vai garantir, não nestes termos necessariamente, a reprodução cada vez mais ampliada do capital e a atenção aos interesses do mercado.

Não se quer aqui, classificar o governo Lula como Novo-Desenvolvimentismo ou não, deixemos para que os historiadores façam isso daqui a alguns anos, pois essa definição neste momento não parece ajudar muito a esclarecer o que se passa com o Estado brasileiro na última década. Mas é preciso levar em consideração este debate nos seus efeitos de poder na vida práticas dos brasileiros, nos esforços de diferenciação entre governos Lula e FHC. As disputas por definição sobre a melhor forma de governar no seio dos mandatos de Lula, e que continua no de Dilma, vai se expressar nas decisões tomadas pelos diversos agentes do Estado brasileiro, como no caso do PAC e de seus princípios. E é isso que se quer investigar.

Assim, quando olhamos de perto e concretamente a realização do PAC, vemos que territorialmente pequenas configurações de poder e de interesses se realizam, então, para garantir, em primeira instância, a manutenção da circulação e da reprodução do capital. Dizemos isso apenas para marcar que não estamos analisando o Programa de Aceleração do Crescimento em si, na sua proposta federal, mas apenas sua materialização na RMRJ, mas, reconhecendo que essa análise particular permite que questões sobre o programa como um todo sejam levantadas.

Essas configurações espaciais podem ser vistas como momentos particulares do que Harvey chama de acumulação por espoliação ou por despossessão $(2003$; 2007). Para o autor, a história dos roubos, fraude e atividades predatórias dentro do capitalismo não se restringiram ao momento que Marx chama de "acumulação primitiva ou original". Ainda hoje, formações sociais ou territórios passam por amplas mudanças institucionais e estruturais para permitir sua inserção no desenvolvimento capitalista. Mecanismos de expropriação que marcaram o momento originário do 
capitalismo ao redor do globo ainda são utilizados, alguns aperfeiçoados, junto com novas formas de roubo de excedente (por exemplo, os direitos de propriedade intelectual). As crises econômicas, espontâneas ou orquestradas, impulsionam a acumulação por despossessão. E, para além da proposta do PAC ser uma nova forma de garantir o crescimento e o desenvolvimento econômico, ele se tornou, dentro governo brasileiro, um elemento essencial para a crise financeira que assolou o globo em 2008. Neste contexto de crise, o PAC se mostra como um momento importante, para garantira propagação da acumulação por despossessão nos termos de Harvey, ao nível de seus objetivos.

Mas, para além disso, a partir da pesquisa feita, vemos que os processos do PAC em algumas áreas estudadas, realmente garante a mercantilização desses territórios, até então, não mercadorizados, seja pelo exemplo do "Minha Casa, Minha Vida", que está dentro do PAC, e foi uma das bases para a produção de habitação no PAC do Projeto Iguaçu por exemplo, que expande uma fronteira de acumulação de capital para o mercado imobiliário, onde antes não havia, seja no exemplo da construção do teleférico do Complexo do Alemão, integrado com linha de trens da Supervia, que foi construído pela Odebrecht, que algum tempo depois veio a adquirir a Supervia e fazer a gestão dos trens urbanos na cidade do Rio de Janeiro, garantindo também o público que utiliza o teleférico.

Neste contexto, nas intervenções analisadas, surgem o que Harvey (2007) chama de "coerências estruturadas". Vemos a construção desses espaços coerentes, onde o capital consegue se reproduzir, sem os constrangimentos do tempo socialmente necessário acelerado para a sua reprodução, navegando e avançando na calmaria das águas, que se mantém sem a tormenta do tempo acelerado, pela intervenção dos agentes públicos, estatais. Que garantem os riscos e a compensação pela reprodução ampliada do capital nestes espaços. No caso de Manguinhos, por exemplo, uma vez acertado os recursos orçamentários das obras, houve uma aditivo de mais de R $\$$ 500 milhões de reais, que não foram garantidos pelo Orçamento da União, mas abriram um espaço de diálogo entre o governo estadual e o BNDES. E os atrasos das obras não se justificam apenas pela falta de repasses para as empreiteiras, mas por uma lógica de trabalho que, de tão antieconômica, só se torna possível com as compensações estatais.

No contexto de uma coerência estruturada e da acumulação, não passam despercebidas as lutas de classe as alianças que surgem das mesmas. Como uma das condicionantes do desenvolvimento desigual capitalista, segundo Harvey (2007), as resistências ou a participação popular na elaboração e fiscalização das obras do PAC foram anuladas, ou terceirizadas e colonizadas (para ONG's, ou outras empresas), no que foi o trabalho social do PAC, ou PAC social. Neste contexto, nas diversas obras analisadas, vemos mais ou menos básicas de articulação capitalEstado, ainda que com atores diferentes (Empreiteiras diferentes, ou entes da federação distintos), mas é possível ver o alijamento popular destas alianças.

Aqui, é interessante retomar as quatro gramáticas políticas sugeridas por Edson Nunes para entender o que se passa (Nunes, 1997; Cardoso e Júnior, 2003): clientelismo (Um sistema de controle de fluxo de recursos materiais e de intermediação de interesses, no qual não há número fixo ou organizado de unidades constitutivas), o corporativismo (o fortalecimento de grupos e seus interesses na relação entre Estado e sociedade), o insulamento burocrático (a emergência e isolamento de um quadro técnico, que devido seu saber, recebem alguma blindagem na tomada de decisões políticas) e o universalismo de procedimentos (princípio no qual os serviços públicos seriam pautadas pela atenção geral e universal de todos os cidadãos do país).

Infelizmente, não há espaço para uma caracterização profunda essas gramáticas, mas é preciso fazer referência a elas, para entender o que se passa com o PAC, ao menos na RMRJ. Primeiro, o que há de novidade no PAC nessas ações territoriais, é o esforço pela blindagem ao 
clientelismo, que pauta há décadas o padrão de relacionamento público entre a sociedade, em particular as camadas mais populares, e o Estado. Em parte isso pode ser explicado pela proposta universalista do PAC, em sua relação institucional direta com o Poder Executivo dos outros níveis de governo, estadual e municipal; o que se expressa no edital aberto para seleção de projetos par ao PAC, numa lógica do agraciamento das propostas mais eficientes. Num princípio de impessoalidade na gestão pública.

Mas outra gramática que nos ajuda a entender a redução do clientelismo e a restrição ao universalismo de procedimentos, mas também o bloqueio da participação popular, é o insulamento burocrático, como uma solução governamental onde os órgão estatais ganham uma certa autonomia na tomada de decisões, que passam a se pautar pela mérito técnico e racional da tomada de decisões. E são esses méritos e critérios racionais, que legitimam e sustentam uma temporalidade do cálculo, muito mais acelerada que a temporalidade política das discussões, que garantem certa autonomia de algumas instâncias estatais e a centralização da tomada de poder, como a centralização da coordenação das obras do PAC na Casa Civil. Aqui há de se acrescentar a necessidade da impulsão da imagem da então ministra Dilma Rousseff, da Casa Civil, para as eleições de 2010.

Se por um lado essa centralização, que se reproduz nos outros níveis de governo, blinda um pouco o clientelismo, ele blinda também a participação popular, uma vez que a produção dos projetos se guiam por critérios eminentemente técnicos, que não são passíveis de discussão com a população, uma vez que o prazo da seleção dos projetos era limitado. Foi a justificativa que se ouviu de agentes públicos responsáveis pela gestão do PAC no governo estadual, nas entrevistas realizadas. Some-se a isso, que os critérios nos editais eram eminentemente técnicos, baseados em diagnósticos; logo, deveriam ser feitos por pessoas qualificadas, do quadro técnico de municípios e estados, ou contratados por assessorias qualificadas para isso, não pelas pessoas que vivem seus problemas cotidianos nos lugares onde vivem.

E essa urgência da seleção de projetos, ainda que "tecnicamente" estabelecida, e a discussão acima da mercantilização de territórios ainda não mercadorizados, convergem para um planejamento estatal nos termos que Chico de Oliveira vai chamar de estado de exceção (2003). Segundo Oliveira (2003), a informalidade como regra, não mais como exceção nas economias subdesenvolvidas, mais a autonomização do mercado, fortalecida pela financeirização, levam os Estado a buscar, com suas políticas, não mais distribuir renda, mas funcionalizar a pobreza, no nosso ver, isto é, mercadorizá-la. Nesta lógica, a exceção é a regra, não é mais uma anormalidade e o subdesenvolvimento não é mais transitório, mais veio para ficar; ele é a singularidade de quem não pode reproduzir o original, o capitalismo e o desenvolvimento dos países do norte. E o PAC, as respostas para crise do governo brasileiro e mesmo o novo-desenvolvimentismo, podem ser enquadrados nesta ótica, de respostas a um subdesenvolvimento que veio para ficar.

Nesta lógica, o Estado, e o planejamento, se tornam de exceção, pois é o soberano que decide o que é exceção, e esse soberano é o mercado. É a atenção dos seus interesses, como visto em alguns dos dados coletados na pesquisa e a lógica da acumulação por despossessão que orientou o PAC na RMRJ, que são prementemente atendidos. A isso se soma o fato que dos eixos do PAC, o do desenvolvimento social foi o menos contemplado, perdendo feio, em nível de recursos, para os investimentos em logística e infraestrutura econômica.

A gestão, e não o planejamento, predomina. A gestão é marcada por uma temporalidade acelerada, da urgência. É nessa lógica que operou a seleção dos projetos do PAC e garantiu, como vimos, o afastamento da participação popular da construção das intervenções realizadas. Essa é a dinâmica também, de uma cidadania escassa (Rezende, 1996). 
A cidade, lugar por excelência das exceções, segundo Oliveira (ibid) se tornou um objeto de conquista, em um conflito predatório e individualizado. Ela se torna uma cidade pequena porque escassa a sua capacidade de garantir universalmente os direitos fundamentais para todos os seus cidadãos (Carvalho, 2000), e cenário para um tipo específico de sociabilidade, a sociabilidade violenta.

O que caracteriza uma cidade escassa é esse conflito belicoso e permeável a interesses particularistas na apropriação da cidade. No nosso caso, esses interesses particularistas tomam a forma de conflitos técnicos, que no final das contas, vai reproduzir e aprofundar uma desigualdade regional que preexiste. São os municípios e estados lutando entre si por recursos escassos, os menos providos de quadros técnicos e econômicos, para contratar assessorias, saem atrasados e chegam por último. E nas áreas mais pobres desses municípios e estados, que, ao longo do tempo, foram relegados pelo Estado, em seus diversos níveis, seus moradores devem se contentar por estarem recebendo algum recurso, pois sempre tiveram pouco, ou nenhum. De modo que, devem aceitar, em alguma medida, sem reclamar do que estão recebendo, um esvaziamento da participação popular e da gestão democrática da cidade.

\section{CONCLUSÃO}

$\mathrm{O}$ que quisemos trabalhar neste artigo foi contribuir, a partir de uma reflexão a partir de dados de uma pesquisa e monitoramento do PAC, para os debates postos, do novodesenvolvimentismo do governo Lula, e apontamos algumas coisas de como ele se realiza de modo concreto nas intervenções estatais levadas a cabo dentro desta lógica; de modo mais amplo para as formas atuais de gestão de políticas e da gestão urbana; e apontar para os limites que ainda se colocam, sob novas formas, para realização de uma gestão democrática das cidades, que garantam o direito à cidade e a participação popular.

Toda a lógica apresentada nessas considerações finais, fruto de uma pesquisa que durou três anos, caminhou no sentido, não de dizer que o PAC foi bom ou ruim para as pessoas, pois frente a anos de abandono de determinadas regiões, o PAC trouxe melhorias consideráveis, ao menos nas áreas estudadas, para seus moradores. Mas ele também coloca alguns limites e elementos que nos permitem avaliar de modo mais satisfatório e com algum distanciamento, o quanto ele tem de continuidade e descontinuidade com o que foi feito na gestão urbana desde há décadas no Brasil e o quanto ele iluminas os desafios que ainda se colocam para uma gestão mais democrática de nossas cidades.

\section{REFERENCIAS}

ARAÚJO, J.B.O. Cidadania escassa, controle negociado e os movimentos populares em favelas: reflexões a partir do estudo de caso do Fórum Social de Manguinhos, no Rio de Janeiro. Dissertação de Mestrado, Rio de Janeiro, IPPUR/UFRJ, 2011.

CARDOSO, A.L.; SANTOS JUNIOR, O.A. Avaliação de Políticas Públicas: notas na perspectiva da gestão democrática e da ampliação da cidadania. In: OLIVEIRA, A. F.; NASCIMENTO, C. G.(Org.). Cidades Sustentáveis: políticas públicas para o desenvolvimento. Goiânia, Ed. da UCG., 2006.

CARVALHO, M.A.R. Cidade escassa e violência urbana. In: Série Estudos. Rio de Janeiro, v. 91, p. 259-269, 1995.

CHRISTOVAO, A.C., CID, G.V.S. Espaços da cidadania e monitoramento do PAC: o caso da região metropolitana do Rio de Janeiro. Revista Proposta. Rio de Janeiro, v.120, p.39-46, 2010.

CHRISTOVAO, A.C.; SANTOS, M.R.M. A Baixada Fluminense e o PAC: Reflexões na Perspectiva do Direito à Cidade. Seminário Nacional Governança Urbana e Desenvolvimento Metropolitano. Anais... Natal, 2010. 
FIGUEIREDO, M. F.; FIGUEIREDO, A.M.C. Avaliação política e avaliação de políticas: um quadro de referência teórica. São Paulo, IDESP. 1986.

FOUCAULT, M. O Nascimento da Biopolítca. São Paulo, Martins Fontes. 2008.

HARVEY, D. O Novo Imperialismo. São Paulo, Edições Loyola, 2a Ed. 2003.

. A produção capitalista do Espaço. São Paulo, Annablume, 2a Ed. 2006.

. Notas hacia una teoría del Desarrollo Geográfico Desigual. GeoBaires. Cuadernos de Geografia Apuntes de geografia y ciencias sociales. Buenos Aires, UBA- FFyL. 2007.

NUNES, E.O. A gramática política do Brasil: clientelismo, corporativismos e insulamento burocrático. Rio de Janeiro, Jorge Zahar Ed. 1997.

OLIVEIRA, F. O Estado e a exceção ou o Estado de exceção?. Revista Brasileira de Estudos Urbanos e Regionais, v.5, n.1. 2003

PINHO, C.E.S. O Nacional-Desenvolvimentismo e o Novo-Desenvolvimentismo no Brasil: trajetórias, similitudes e contrastes. Ponto de Vista, Rio de Janeiro, v. 2, 2011.

. O Nacional-Desenvolvimentismo e o Novo-Desenvolvimentismo no Brasil: expansão interna, externa e o discurso socialdemocrata. Achegas.net, v. 45, 2012. 